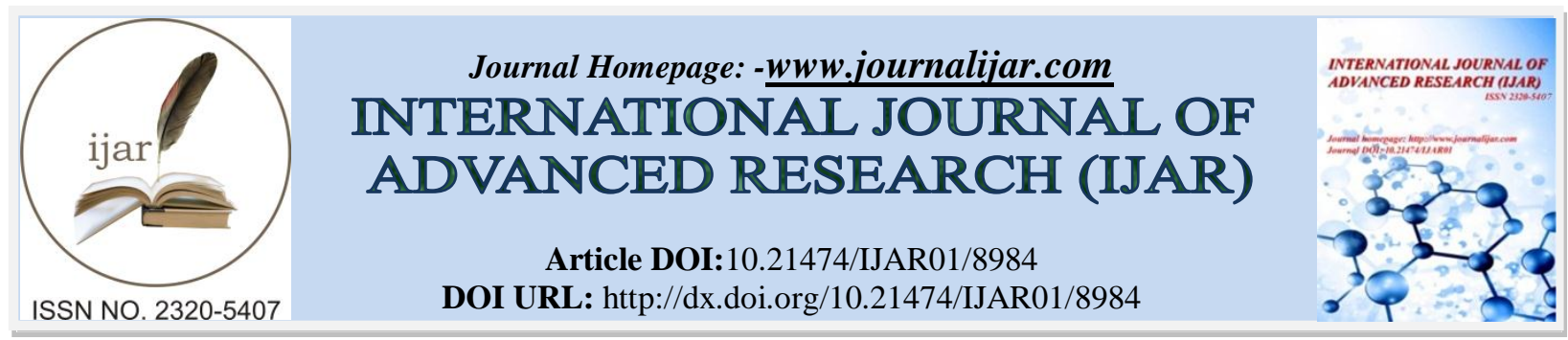

RESEARCH ARTICLE

\title{
HIV AND AIDS: A SURVEY AMONG DENTAL STUDENTS.
}

\section{Dr. Nawal Khan ${ }^{1}$, Dr. Munaza Shafi ${ }^{2}$ and Dr. Shahnaz Nabi ${ }^{3}$.}

1. Post graduate student, Krishnadevaraya College of Dental Sciences, Krishndevarayangar, Hunasamaranhalli, Near-Sri MVIT, Yelahanka, Bengaluru, Karnataka 562157.

2. Senior Resident, SKIMS, Soura.

3. Lecturer, Dept. Of Conservative Dentistry, GDC, Srinagar.

\section{Manuscript Info}

\section{Manuscript History}

Received: 25 February 2019

Final Accepted: 27 March 2019

Published: April 2019

Key words:-

HIV, Dentists, Survey, Knowledge.

\begin{abstract}
Introduction: One of the cornerstones in the fight against HIV/AIDS is the knowledge regarding the disease. The present survey aimed primarily at assessing the knowledge of dental students in Krishnadevaraya College of Dental Scienceson HIV/AIDS.

Materials and Methods: Pre-formed questionnaire of 25 questions was given out to 100 dental students aged between $18-25$ years willing to participate in study. All participants were requested to complete the questionnaire with best of their knowledge and without any assistance. Questionnaire once completed were collected back personally.

Results: Majority students (80\%) had generally positive attitudes about patients with HIV and AIDS. About $12 \%$ expressed discomfort with taking a patient's sexual history Most of the students (96\%) knew that HIV/AIDS patients can infect dental workers and $10 \%$ were unaware of the fact that HIV/AIDS patients can be diagnosed with oral manifestations.

Conclusions: All the students were aware of HIV/AIDS. The majorty of participants demonstrated an adequate understanding of HIV transmission and prevention. In order to combat these issues, effective learning interventions must be introduced.
\end{abstract}

Copy Right, IJAR, 2019,. All rights reserved.

\section{Introduction:-}

Human Immunodeficiency Virus (HIV) is a retrovirus that leads to immune deficiency in humans, now considered as a chronic condition but still remains a serious concern. ${ }^{1}$ HIV has spread rapidly throughout the world since the first case was recognized in the United States in $1981 .^{2}$

Young people are mainly susceptible to the HIV. Over half of all new infections worldwide are among young people between the ages of 15 and $24 .{ }^{3}$ Oral manifestations of HIV infection may be in the form of dental caries, hairy leukoplakia, oral candidiasis, necrotizing ulcerative periodontitis, oral ulcers, linear gingival erythema, parotid swelling, Kaposi sarcomas. ${ }^{4,5}$ These patients seek oral dental procedures as compared with similar patients without HIV/AIDS. Exposure to the blood of an infected patient may cause infection. This may occur via needle stick or a splash to exposed mucous membranes. Invasive oral procedures involving contact with saliva and blood that may contain HIV. ${ }^{6,7}$ Oral manifestations of HIV/AIDS present during the initial stages of the disease, making dentists 
high risk category for cross contamination. ${ }^{7}$ Cross-infection, from an infected patient to the dentist and further from the dentists to other patients may also be seen. ${ }^{8}$

The aim of the study was to review the knowledge and attitude of dental students which helps in understanding their preparedness for treating HIV/AIDS patients. This also helps to understand if any modifications need to be integrated into the curriculum to instil positive attitudes in dental students. We compared the differences in HIV/AIDS related knowledge and attitude between the genders and years of study.

\section{Method:-}

Subjects: The present cross-sectional questionnaire survey was conducted among the First, Second, Third and Final year bachelor students majoring in Dentistry. A total of 100 students participated in the study, 25 students from each year. The participation of the students was voluntary. This survey was aimed to investigate and evaluate their knowledge and attitudes toward the patients suffering from HIV infection/AIDS. Exclusion criteria included students who were not willing to participate and those who were absent on the day of study.

Data collection: A self-made questionnaire was used for the present study. The first part of the questionnaire was used to collect information on gender and year of study while the later part consisted of 25 questions related to the knowledge and attitudes towards HIV/AIDS. The Questionnaire is give at the end.

Survey Questionnaire: The first ten questions were related to knowledge of HIV infection, transmission patterns, and opinions about adequacy of their own knowledge. The answer for knowledge questions was either "agree" or "disagree." A score of 1 was given for correct answer and a zero for the wrong. Hence, a student's total score ranged from 0 to 10 . In the later part of the questionnaire, fifteen questions addressed attitudes towards HIV/AIDS patients, attitudes in treating HIV/AIDS positive patients and ability in treating HIV/AIDS patients. The answer to each question about attitudes was rated on a five-point Likert scale: Strongly agree (SA), Agree (A), Neutral, Disagree (D) and Strongly Disagree (SD). For positive attitudes, a score of 5 was given to the response 'strongly agree' and a score of 1 was given to "strongly disagree" while a score of 5 was given to the response 'strongly disagree" and a score of 1 was given to "strongly agree" for the negative attitudes. Thus the total score for attitudes ranged from 15 to 75 .

\section{Results and discussion:-}

Overall knowledge and awareness on HIV/AIDS among study subjects ranged from $68 \%$ to $95 \%$. About $94 \%$ knew ELISA is a screening test, suggesting good knowledge about diagnostics. However the figures are on higher side when compared to study done by Reshma et al, and Sadeghi et al. ${ }^{9} 76 \%$ of students agreed that HIV/AIDS patients can be suspected from oral manifestations, which is lower in comparison to similar study done by Sadeghi et al, where the response was $95.2 \% .^{9} 95 \%$ of students said that transmission of HIV can occur through needle stick injury which are slightly on lower side when compared to studies conducted by Patil et al and Awad et al. ${ }^{10,11}$ About AIDS as an important health problem in the world $94 \%$ responded correctly which was higher in comparing to study conducted by Deepak et al, and Awad et al. ${ }^{11,12}$ Aerosols from hand pieces as a vehicle for transmission of HIV infection was stated by $66 \%$, as compared to a study conducted by Awad et al, where the response rate $48.8 \%$. ${ }^{11}$ Around $89 \%$ answered correctly the question on spread of HIV by touching, kissing, sharing food and drinks. Whether saliva can be a vehicle for transmission of HIV infection, 53.8\% responded correctly, which is similar to a study done by Abhimanyu et al. ${ }^{13}$ This could be attributed to the difference of opinion and information in literature on the transmissibility of HIV via salivary route. Transmission of HIV from saliva is considered to be a rare event as the saliva in infected patients usually contains only non-infectious constituents of HIV (Baron et al., 1999). ${ }^{3}$ Though these attitude scores are encouraging, there are dental students who still have fear of HIV contagion and AIDS phobia from their friends and colleagues.

Also, 95\% strongly agreed/agreed (SA/A) that it was their moral responsibility to treat HIV/AIDS patients and risk of HIV contagion is high, hence special precautions have to be followed to treat them. 76\% SA/A to deliver emergency care; 94\% considered their right know the HIV status of their patients; $89 \%$ said that they will treat them; 84\% said that HIV patients can lead a normal life; $73 \%$ felt that HIV patients can be safely treated. $90 \%$ strongly disagreed/disagreed (SD/D) that if friend has HIV, will end relationship; 91\% SD/D to stop working with a colleague with HIV infection. 94\% SD/D with treating HIV is waste of resources; 60\% SD/D that dentists with 
HIV/AIDS should not be allowed to practice. $90 \%$ of students showed a positive attitude against $10 \%$ with negative attitude.

Male students reported significantly better attitudes towards HIV/AIDS patients than female students; this is in contrast with a study that was conducted in US (Seacat and Inglehart, 2003). ${ }^{3}$ The results also showed that students' knowledge and attitudes on HIV/AIDS increased as the year of study progressed.

\section{Conclusion:-}

From the present study, we conclude that overall students have a good knowledge and a positive attitude towards HIV/AIDS patients. Active student's collaboration for treatment compliance of HIV/AIDS patients should be directed towards comprehensive training in the dental colleges which forms a basis for provision of appropriate, optimal dental care improving oral health related quality of life in people living with HIV. Management and precautionary measures in dental practice should be introduced during the initial years of the course itself to make the students competent enough to manage these patients.

\section{Questionnaire}

1. HIV infection can spread by touching, kissing, sharing food and drinks.

2. Needle stick injury during dental treatment can transmit HIV.

3. Saliva can be a vehicle for transmission of HIV infection.

4. Aerosols from hand pieces can be a vehicle for transmission of HIV infection.

5. ELISA test is screening test for HIV infection.

6. Western blot test is a confirmative test for HIV infection.

7. HIV/AIDS patients can be diagnosed with oral manifestations.

8. HIV/AIDS patients can contaminate dental workers.

9. Medical and paramedical staff is more prone for HIV infection.

10. Dentists can act as an intermediary for transmission of HIV.

11. It is my moral responsibility to treat HIV/AIDS patient.

12. One can safely treat HIV/AIDS patients.

13. I will treat HIV/AIDS patients.

14. Risk of HIV contagion is high, hence special precautions have to be followed to treat HIV/AIDS patients.

15. HIV/AIDS patients can lead a normal life.

16. Patient's status of HIV infection should be disclosed to all the family members of the patient.

17. All dental patients should be considered as potentially infectious.

18. If I know my friend has HIV infection, I will end the relationship.

19. If my colleague is HIV infected, I will stop working with him/her.

20. Treatment of HIV/AIDS patients means wasting national resources.

21. Supporting HIV/AIDS patients improves community health.

22. I will deliver emergency care to HIV/AIDS patients if need arises.

23. I worry about being infected with HIV by my patients.

24. It is my right to know if my patients are infected by HIV.

25. Dentists with HIV/AIDS should not be allowed to practice.

\section{References:-}

1. Rani V, Dumpala S, Shyamala R. Knowledge and attitude among students towards HIV/AIDS patients at a dental college, Suraram, India. Int J Basic Clin Pharmacol 2017; 6:2646-50.

2. Tan X, Pan J, Zhou D, Wang C, Xie C. HIV/AIDS knowledge, attitudes and behaviors assessment of Chinese students: a questionnaire study. Int J Environ Res Public Health. 2007; 4(3):248-253.

3. Kumar S, Tadakamadla J, Areeshi AYBH, Tobaigy HAWM. Knowledge and attitudes towards HIV/AIDS among dental students of Jazan University, Kingdom Saudi Arabia. Saudi Dental Journal. 2018; 30: 47-52.

4. Coogan MM, Greenspan JCS, Challacombe SJ. Oral lesions in infection with human immunodeficiency virus. Bull of the World Health Organization. 2005; 83(9):700-6.

5. Cohen LA, Romberg E, Grace E. Revisiting the attitudes of dental faculty toward individuals with AIDS. J Dent Edu. 2001; 65(3):249-52.

6. Oliveira ER, Narendran S, Falco A. Brazilian dental students knowledge and attitude towards HIV infection. AIDS Care. 2002; 14(4):569-76. 
7. Erasmus S, Luiters S, Brijlal P. Oral hygiene and dental students knowledge, attitude and behaviour in managing HIV/ AIDS patients. Int J of Dent Hyg. 2005; 3(4):213-17.

8. McCarthy GM, Koval JJ, MacDonald JK. Factors associated with refusal to treat HIV-infected patients: the results of a national survey of dentists in Canada. Am J Public Health. 1999; 89(4):541-45.

9. 14. 9. Sadeghi M, Hakimi H. Iranian dental students knowledge of and attitudes towards HIV/AIDS patients. J Dent Educ. 2009; 73(6):740-5.

10. Patil PB, Sreenivasan V, Goel A. Knowledge of HIV/AIDS and attitude of dental students towards HIV/AIDS patients: A cross-sectional survey. J Educ Ethics Dent. 2011; 1(2):59-63.

11. Alsamghan AS. Knowledge and attitude of male dental students toward HIV/AIDS in King Khalid University, Saudi Arabia. Int. J. Public Health Epidemiol. 2012; 1(1):1-8.

12. Singhal DK, Charya S, Sharma K. Knowledge and attitude of dental students towards HIV/AIDS patients: A questionnaire survey. JIARM. 2014; 2(3):703-11

13. Chauhan AS, Hussain MA, Pati S, Nallala S, Mishra J. Knowledge and attitudes related to HIV/AIDS among medical and allied health sciences students. Indian Journal of Community Health. 2011; 23(2):96- 8. 